\title{
CURSO DE INGLÊS A DISTÂNCIA UTILIZANDO UM PLANEJAMENTO TEMÁTICO BASEADO EM TAREFAS: O PROFESSOR COMO AGENTE DE ESCOLHA
}

\author{
Denise Elaine EMIDIO* \\ Rita de Cássia BARBIRATO**
}

- RESUMO: O advento das novas tecnologias trouxe o ensino de línguas para o ambiente virtual de aprendizagem. Na tentativa de contemplar os preceitos da abordagem comunicativa (ALMEIDA FILHO, 2002, 2005, 2012) e do planejamento temático baseado em tarefas (PTBT) (SKEHAN, 1996; XAVIER, 1999, 2007; BARBIRATO, 1999, 2005; FRANSCESCHINI, 2014) foi oferecido um curso de inglês a distância pela plataforma Moodle aos alunos de uma instituição federal de tecnologia. O tema escolhido para o curso foi Inventores e Invençóes e as unidades temáticas do material contemplaram aspectos da vida e das invenções de Nikola Tesla e Leonardo da Vinci. O objetivo deste artigo, portanto, é apresentar e discutir resultados advindos dessa pesquisa de doutorado analisando o papel do professor na elaboração desse material temático baseado em tarefas para o curso. A análise dos dados apontou para o papel determinante do professor nos desafios e escolhas na preparação do referido material.

- PALAVRAS-CHAVE: PTBT. Ensino e aprendizagem de inglês. Plataforma Moodle.

\section{Introdução}

Com o advento das novas tecnologias e com a internet, o oferecimento de cursos a distância ${ }^{1}$ se faz uma realidade na educação atual. Os cursos de línguas também são oferecidos por meio de ambientes virtuais de aprendizagem ${ }^{2}$ (AVAs), dentre eles, a

\footnotetext{
* UFSCar - Universidade Federal de São Carlos - Pós-Graduação em Linguística. São Carlos - SP Brasil. 13565-905 - deniseelainee@yahoo.com.br

** UFSCar - Universidade Federal de São Carlos. Centro de Educação e Ciências Humanas Departamento de Letras. São Carlos - SP - Brasil. 13565-905 - ritabarbi.m@gmail.com

1 Esses cursos se caracterizam por utilizarem um computador com acesso à internet que possibilita momentos de interação síncrona (online) e assíncrona (off-line).

2 De acordo com Almeida (2003), esses ambientes são sistemas computacionais disponíveis na internet que permitem integrar diferentes mídias, linguagens e recursos, apresentar informaçóes, desenvolver interaçóes, produzir e socializar produçóes, independente do tempo e do espaço de cada participante.
} 
plataforma Moodle. Com o intuito de utilizar os preceitos da abordagem comunicativa (ALMEIDA FILHO, 2002, 2005, 2012) e os princípios do planejamento temático baseado em tarefas (PTBT) (SKEHAN, 1996; XAVIER, 1999, 2007; BARBIRATO, 1999, 2005; FRANCESCHINI, 2014), foi oferecido um curso de extensão de inglês a distância aos alunos de cursos técnicos, tecnológicos e superior de uma instituição federal de tecnologia. O material do curso foi elaborado por uma professora-pesquisadora que produziu atividades e tarefas comunicativas com foco no sentido na plataforma Moodle. Almeida Filho e Barbirato (2000, p.25) definem tarefa como uma atividade que envolve "[...] o uso comunicativo da língua no qual a atenção do usuário está focalizada no significado e não na estrutura linguística." Nesse sentido, Massarotto, Souza e Barbirato (2009, p.116) complementam a definição de tarefa salientando que "tem sempre um objetivo a ser alcançado pelo aprendiz". Como tema do curso, optou-se por Inventores e Invençóes e foram elaboradas duas unidades temáticas as quais contemplaram aspectos da vida e das invençóes de Nikola Tesla e de Leonardo da Vinci.

A partir de pesquisas realizadas por Barbirato $(1999,2005)$ constatou-se que a utilizaçáo de um único tema macro para esse tipo de planejamento, pode proporcionar maior reentrada de insumo o qual pode "[...] contribuir para a aquisição de vocabulário e para um aumento de insumo compreensível para os aprendizes [...]" (MASSAROTTO; SOUZA; BARBIRATO, 2009, p. 118).

A realização de estudos sobre a utilização de um planejamento temático baseado em tarefas com foco no sentido justifica-se pelo reconhecimento de que várias pesquisas têm sido realizadas e têm se mostrado bastante promissoras ao contribuir com o desenvolvimento da competência comunicativa (ALMEIDA FILHO, 2002) dos aprendizes. No entanto, muitas destas pesquisas ainda focam aspectos teóricos, necessitando-se, portanto, de estudos que foquem aspectos empíricos do uso de tarefas em sala de aula de língua estrangeira (LE).

Outra justificativa para a implementação de um PTBT no ambiente virtual é que o uso de tarefas em sala de aula de LE ainda é insipiente ou até mesmo equivocado (XAVIER, 2007). Ora os professores as utilizam como um apêndice da aula para a prática oral, ora as utilizam como uma atividade extra em sala de aula para praticar uma estrutura linguística estudada anteriormente (MASSAROTTO; SOUZA; BARBIRATO, 2009). Portanto, julgamos que mais pesquisas são necessárias para esclarecer esse trabalho com tarefas com foco no sentido em sala de aula de línguas tanto em contexto presencial quanto no virtual.

Embora saibamos que alguns autores (WIDDOWSON, 1991; SKEHAN, 2003 e outros) argumentem que tarefas com foco no sentido não são suficientes para a precisão gramatical, defendemos que no PTBT, os aspectos gramaticais sejam trabalhados mediante a necessidade detectada pelo professor ou apontada pelo aluno. Assim, como Barbirato (1999), acreditamos que a atençáo do aluno deva estar voltada para o significado, e ele deve ser capaz de utilizar a forma como um instrumento para a comunicação. 
Além das justificativas apresentadas, há constatação de muito pouco desenvolvimento de materiais a partir de um PTBT. Além disso, podemos observar que nos materiais que se declaram baseados em tarefas e que estão disponíveis no mercado para o ensino presencial, as tarefas são utilizadas no final dos estágios, como prática linguística (BARBIRATO, 2005).

Pretendemos neste artigo analisar e discutir o papel do professor na elaboração de um material temático baseado em tarefas para o ensino de inglês em contexto virtual descrevendo os desafios enfrentados pela professora e as suas escolhas mediante as opçóes de ferramentas da plataforma Moodle que possuía.

\section{Planejamento Temático Baseado em Tarefas}

Uma vez que o material elaborado pela professora-pesquisadora teve como eixo organizador o planejamento temático baseado em tarefas é, imprescindível apresentarmos, primeiramente, alguns preceitos da abordagem comunicativa na qual este tipo de planejamento está inserido.

A abordagem comunicativa teve grande destaque no Brasil por volta da década de 80 com o objetivo de atender à demanda por um ensino de línguas mais contextualizado, relevante e significativo para o aprendiz (ALMEIDA FILHO, 2002, 2005, 2012).

Segundo Richards (2005), a competência gramatical possibilitava a produção de sentenças gramaticalmente corretas, no entanto, era necessário atender a outras finalidades comunicativas como utilizar a língua para a comunicação. O autor enfatiza que para se comunicar efetivamente o falante precisava mais do que conhecimentos de regras gramaticais, era necessário que ele fosse capaz de usar esses conhecimentos em situaçôes comunicativas, como "fazer solicitaçôes", "dar conselhos", "fazer sugestôes", "descrever vontades e necessidades" em "práticas discursivas propositadas".

Barbirato (1999) destaca que com o advento da abordagem comunicativa, houve, por parte de profissionais envolvidos com a área de ensino e aprendizagem de LE, um interesse em se produzir materiais didáticos proclamados comunicativos. O problema, segundo a autora, está no fato de que não basta adotar "[...] um material que se diga comunicativo para se desenvolver realmente uma prática comunicativa na sala de aula [...] é necessária uma reflexão cuidadosa sobre os princípios subjacentes a esta abordagem [...]" (BARBIRATO, 1999, p.47). É necessário que o professor reflita sobre a sua abordagem de ensinar para que realmente possa ser comunicativo, ao invés de adotar um material comunicativo e possuir uma abordagem estrutural. A concepção de língua, linguagem e cultura de ensinar de um professor podem fazer com que ele utilize os princípios de um ensino estrutural ou de um ensino comunicativo, o material, portanto, náo é suficiente para determinar tal atitude docente.

Outro fator importante a ser considerado ao desenvolver um PTBT é a compreensão do professor sobre a diferença entre tarefa, atividade e exercício. De acordo com Almeida Filho e Barbirato (2000, p.29), "toda tarefa é uma atividade, 
mas nem toda atividade é tarefa”. Para os autores, a tarefa é diferente de exercício, pois a primeira tem como elemento central o sentido, enquanto que o segundo tem foco na forma, no emprego de regras linguísticas e no uso extensivo de exercícios mecânicos de automatização.

É fundamental que o professor tenha claro que, como defende Almeida Filho (2002), o ensino comunicativo proporciona experiências relevantes e de interesse dos alunos, permitindo que eles utilizem a língua-alvo para interagir com outros falantes dessa língua.

Com base nos preceitos do ensino comunicativo de língua surge o planejamento temático baseado em tarefas (PTBT). Segundo Frost (2006), a utilização do PTBT traz vantagens significativas para os aprendizes, uma vez que estes podem se sentir mais autônomos no processo de aprendizagem da língua-alvo ao utilizarem os recursos linguísticos de que dispóem, ao invés de serem obrigados a praticar uma estrutura específica.

Além do papel do aluno, o papel do professor também é revisto nesse tipo de planejamento. De acordo com Barbirato (2000), o professor passa a ser um facilitador, gerenciador da realização das tarefas e de sua elaboração. Ele deve ser um incentivador e propiciador de um ambiente descontraído, no qual os alunos poderáo se expor oralmente sem constrangimentos.

Além dessas transformaçóes no processo de ensino e aprendizagem de línguas, o oferecimento do insumo para o aprendiz por parte do professor no PTBT passa a ser de melhor qualidade, ou seja, mais significativo e relevante, propiciando, assim, "experiências mais diretas com e na língua-alvo" (ALMEIDA FILHO; BARBIRATO, 2000, p.24).

Segundo Massarotto, Souza e Barbirato (2009, p.116), o planejamento temático baseado em tarefas "tem como uma das suas principais características ser organizado em torno de tarefas as quais devem ser realizadas pelos aprendizes na língua-alvo". Dessa forma, "[...] a tarefa passa a ser o elemento central deste planejamento aliada a um tema macro o qual contribui para que as tarefas e o insumo sejam gerados [...]" (MASSAROTTO; SOUZA; BARBIRATO, 2009, p.116).

Após apresentadas as consideraçóes sobre o ensino comunicativo e o planejamento temático baseado em tarefas, passamos, na seção seguinte, a explanar sobre a plataforma Moodle e suas ferramentas.

\section{A Plataforma Moodle}

A palavra Moodle é um acrônimo para Modular Object-Oriented Dynamic Learning Environment (Ambiente de Aprendizagem Dinâmico Modular Orientado a Objeto). É interessante mencionar que, segundo Cole e Foster (2008) Moodle também é

Para maiores informações acessar http://www.moodle.org. 
um verbo que descreve o processo de passar por algo tranquilamente, executando as coisas conforme elas ocorrem de uma maneira agradável levando à introspecçáo e à criatividade. Assim, para Franco (2009) essa palavra representa a forma como o programa foi desenvolvido, mas também o modo como se espera que os usuários o utilizem em um curso a distância, por exemplo.

A plataforma Moodle foi criada pelo australiano Martin Dougiamas nos anos de 1990. De acordo Cole e Foster (2008, p.4) o desenvolvimento dessa plataforma foi inspirado na epistemologia sócio-interacionista, que se baseia na ideia de que "as pessoas aprendem melhor quando estão engajadas em um processo social de construção de conhecimentos, construindo artefatos para outros" " (COLE; FOSTER, 2008, p. 4, tradução nossa). Além disso, Dougiamas (2000) considerou tanto a perspectiva do aluno como a do professor ao desenvolver a plataforma Moodle.

Essa plataforma oferece diferentes recursos incluindo ferramentas para a produção e o armazenamento de conteúdos, para a comunicação síncrona e assíncrona e para a administração e gerenciamento de cursos. Além de diversas outras que podem ser utilizadas pelos usuários para postarem atividades, debaterem em fóruns de discussão, tirarem suas dúvidas através de mensagens e desenvolverem outros modos de interação.

Dentre as ferramentas disponibilizadas por essa plataforma, podemos citar quatro grupos organizados por Gonzales (2005) mediante a suas funcionalidades. O primeiro grupo são as denominadas de coordenação, pois oferecem suporte metodológico, estrutural e pedagógico para a organização de um curso on-line; o segundo grupo são as de comunicação, que estimulam a interação entre os participantes, como, por exemplo, fóruns de discussão e chat; o terceiro grupo são as de cooperação, que permitem a publicação de textos dos alunos através do perfil, por exemplo; o quarto grupo são as de administração, que disponibilizam recursos de gerenciamento do curso, de alunos e de material didático.

A versão da plataforma disponibilizada pela instituição onde o curso foi oferecido disponibiliza dois tipos de ferramentas: as atividades (base de dados, chat, escolha, ferramenta externa, fórum, glossário, laboratório de avaliação, lição, pesquisa de avaliação, questionário, SCORM/AICC, tarefa e wiki) que são ferramentas destinadas à avaliação e comunicação e os recursos (arquivo, conteúdo do pacote IMS, livro, página, pasta, rótulo e URL) que têm a função de fornecer base para o conteúdo que o aluno irá receber.

Vimos, por meio das setas nas figuras a seguir, demonstrar as ferramentas utilizadas pela professora na elaboração do material do curso.

\footnotetext{
4 "Social constructionism is based on the idea that people learn best when they are engaged in a social process of constructing knowledge through the act of constructing an artifact for others." (COLE; FOSTER, 2008, p. 4).
} 
Figura 1 - Indicação das Ferramentas utilizadas pela professora

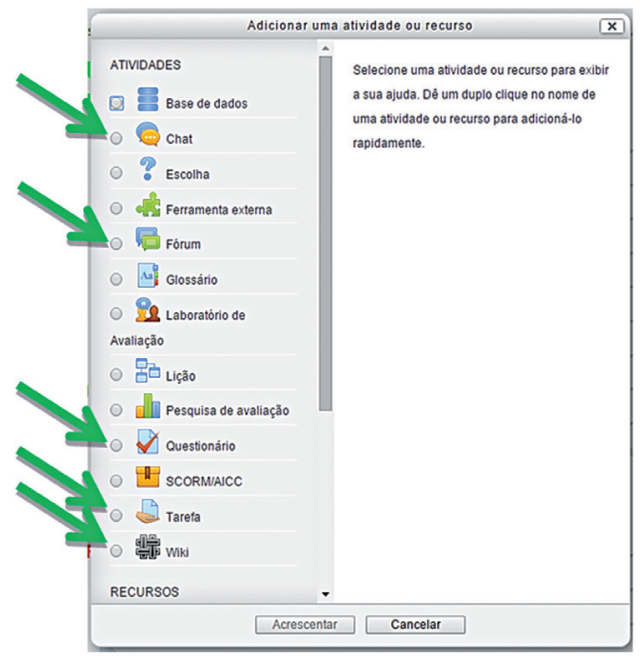

Fonte: Plataforma Moodle.

Como podemos observar na figura acima, as ferramentas utilizadas pela professora foram o chat, o fórum, o questionário, a tarefa, ou também, chamada de envio de arquivo e a wiki.

Apesar de tentar utilizar o máximo de ferramentas disponíveis por essa versão da plataforma Moodle na elaboração das tarefas, alguns fatores dificultaram o uso. Discutiremos essas dificuldades mais adiante, no entanto, vale adiantar que fatores como a abordagem da professora, a falta de conhecimento técnico prévio, a limitação de algumas ferramentas e as experiências como aluna e docente de língua inglesa influenciaram diretamente o uso e a escolha das ferramentas pela professora para a elaboração do material.

Apresentadas a plataforma Moodle e suas ferramentas. Nas duas seçóes seguintes serão relatados a metodologia da pesquisa, o curso de inglês a distância e o perfil do alunado.

\section{Metodologia da pesquisa}

Este estudo se caracterizou como qualitativo-interpretativista ${ }^{5}$ (MOITA LOPES, 1996) de base etnográfica virtual ${ }^{6}$ (AMARAL; NATAL; VIANA, 2008). Para a coleta

\footnotetext{
5 De acordo com Moita Lopes (1996, p.22), na pesquisa qualitativa-interpretativista o foco "é no processo de usa da linguagem".

6 Segundo Mercado (2012, p. 169), a pesquisa de etnografia virtual “[...] estuda as práticas sociais na internet e o significado destas para os participantes. [...] Estuda as experiências pessoais que emergem na comunicaçáo mediada pelo computador."
} 
dos dados deste recorte que apresentamos aqui, foram utilizados registro das interaçóes entre a professora e os alunos (na plataforma Moodle, no Facebook e no Skype), o material elaborado pela professora (na plataforma Moodle), e o registro das tarefas realizadas pelos alunos (na plataforma Moodle).

\section{O curso de inglês a distância e o perfil do alunado}

Apesar de associarmos o ensino a distância à internet, esse tipo de ensino já existia muito antes dela. Segundo Moore e Kearsley (2008), o ensino a distância evoluiu ao longo de cinco geraçôes, passando pela correspondência, pela transmissão por rádio e televisão, pelas universidades abertas, pela teleconferência e pela atual, internet.

O curso de extensáo de inglês foi realizado no primeiro semestre de $2015 \mathrm{em}$ um campus de uma instituição federal de tecnologia no interior de São Paulo. Ele foi ofertado na modalidade a distância pela plataforma Moodle disponibilizada pelo campus da Instituição e possuía uma carga horária de 40 horas distribuídas em oito semanas de atividades.

Participaram do curso 29 alunos de cursos técnicos, tecnológicos e de graduação, sendo que quatro deles o concluíram até o final. As áreas de estudos desses alunos eram na sua maioria de exatas, sendo os cursos: ciências da computação, análise e desenvolvimento de sistemas, engenharia elétrica, engenharia civil, engenharia da computação, meteorologia e tecnologia em mecatrônica. Além do curso de licenciatura em matemática, em letras e em geografia.

A professora baseando-se em experiências docentes anteriores considerou que o assunto do curso Inventores e Invençóes seria motivador e relevante para esse tipo de aluno, uma vez que esses estudantes lidam com inventos, descobertas, patentes, manuais de funcionamento, vida e obra de inventores e pesquisadores em sua rotina de estudo e de trabalho. Selecionado o tema e por já ter experienciado o trabalho de docência em um curso técnico de eletrônica, a professora optou por explorar aspectos da vida e das invençôes de Nikola Tesla. Além disso, ela julgou relevante trazer para esse contexto aspectos da vida e das invençôes de Leonardo da Vinci.

Para elaborar o material, a professora utilizou os preceitos do PTBT, ou seja, tarefas focadas no sentido e com resultado comunicativo e as ferramentas disponibilizadas pela versão da plataforma Moodle oferecida pelo campus da instituição.

Descritos os instrumentos de pesquisa, o curso e o perfil do alunado, passemos, na próxima seção, à análise dos dados.

\section{Análise dos dados}

Por meio da análise dos dados, pudemos constatar que a professora enfrentou alguns desafios na elaboração do material para o curso. Dentre eles podemos citar a sua abordagem, a falta de conhecimento técnico prévio, a limitação de algumas ferramentas 
e as experiências como aluna e docente de língua inglesa. Esses fatores influenciaram diretamente o uso e a escolha das ferramentas pela professora para a elaboraçáo do material. Vimos, agora, analisar esses fatores.

\section{A abordagem da professora}

A elaboração do material para o curso passou por duas fases. A primeira fase aconteceu seis meses antes, na oferta de um curso piloto na mesma instituição. Durante a aplicação desse piloto e após o seu término, a professora reconheceu que havia certa incoerência entre a caracterização das atividades que tinham sido elaboradas por ela e os princípios do planejamento temático baseado em tarefas. O PTBT defende o uso de tarefas com foco no sentido e com resultado comunicativo. Porém, ao elaborar o material, a professora produziu atividades de prática conversacional (XAVIER, 2007), de localização de informação e de exercícios de treino da habilidade auditiva e do léxico focando aspectos da forma da língua. A partir da compreensão dessa incoerência na elaboração das atividades, a professora passou para a etapa de reformulação do material tentando se aproximar dos preceitos do PTBT.

A nosso ver essa incoerência da professora ao elaborar as atividades pode ter sido causada por dois fatores principais: primeiramente, o fato de a professora possuir uma abordagem focada na forma da língua, em experiências como aprendiz e como professora de língua inglesa e, em segundo, por não possuir uma clareza conceitual da diferença entre tarefa, atividade e exercício.

A professora, influenciada por sua abordagem e suas concepçóes de língua, linguagem, ensino e aprendizagem de língua estrangeira, reproduziu um padrão de ensino de língua focado na abordagem estrutural. Embora houvesse um desejo de romper com o padrão estrutural do ensino de línguas, essa ruptura não aconteceu da forma desejada devido à forte influência de sua abordagem. Houve a tentativa da professora de romper com esse padrão estrutural. Porém, esse rompimento se concretizou em reprodução do que já existia.

Esses fatores nos fazem pensar na dificuldade de se adequar aos critérios de um planejamento, principalmente para um professor que não possui uma competência teórica (ALMEIDA FILHO, 2002) desenvolvida. Portanto, defendemos que o desenvolvimento da competência teórica, da explicitação da abordagem do professor se fazem necessários para ele conseguir romper com o paradigma estrutural de ensino de língua. Além disso, a formação continuada, a busca pela academia e pela teoria pode oferecer ao professor embasamento teórico para desenvolver o referido planejamento, por exemplo.

Para a professora-pesquisadora, além dessa busca, as orientaçóes com a sua orientadora de doutorado possibilitaram discussóes teóricas importantes para que a docente conseguisse se aproximar da elaboração de tarefas com foco no sentido 
e resultado comunicativo e, assim, ter uma maior coerência com os preceitos do planejamento temático baseado em tarefas.

\section{Falta de conhecimento técnico prévio}

O segundo fator detectado durante a elaboração do material, não menos relevante que o primeiro, diz respeito ao uso das ferramentas da plataforma Moodle. Aprender a manusear essas ferramentas era um desafio e fazer com que elas atendessem ao PTBT era outro. Como a instituição não capacitava seus docentes para utilizar as ferramentas da plataforma Moodle e não havia uma pessoa que pudesse dar suporte técnico nesse aspecto, muitas das descobertas de como manuseá-la aconteceu por meio de tentativas e erros. A professora teve que aprender o funcionamento de cada ferramenta sozinha por meio de tutoriais disponibilizados online e do próprio uso ao elaborar as tarefas no ambiente virtual.

Das ferramentas disponíveis, a professora conseguiu utilizar em seu material do curso o chat, o fórum, o questionário, a tarefa e a wiki. Sendo que da ferramenta "questionário" que apresenta doze tipos de questão, como podemos visualizar na figura 2, a professora utilizou apenas cinco: associação, ensaio, múltipla escolha, resposta curta e verdadeirolfalso.

Figura 2 - Tipos de questão disponíveis na ferramenta questionário

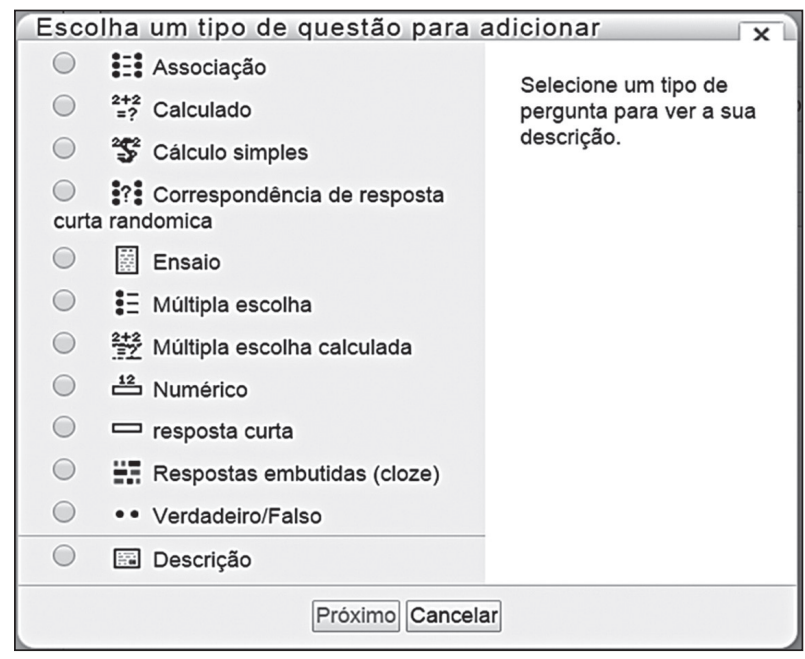

Fonte: Plataforma Moodle.

Os outros tipos de questão foram experimentados para o uso, no entanto, mesmo com a utilização de tutoriais e de tentativas e erros, a professora não obteve sucesso. 


\section{Limitação de algumas ferramentas}

Ao elaborar as tarefas no AVA tentando adequá-las aos princípios do PTBT, a professora deparou-se com limitaçóes advindas de algumas ferramentas. Dentre essas ferramentas limitantes, podemos citar o tipo de questão "resposta curta" do questionário. Este tipo permite uma resposta de uma ou de poucas palavras, que é avaliada pela comparação com vários modelos de respostas já inseridas e gravadas na plataforma. O próprio sistema faz a correção da questão informando ao usuário se a resposta está correta ou não.

No exemplo a seguir (Figura 3), na questáo 2, (Ao assistir ao vídeo e olhar o mapa abaixo, sabemos que um continente foi mudado pelo Renascimento durante a vida de Leonardo. Que continente foi esse?), é pedido que o aluno responda com o nome do continente europeu.

Figura 3 - Questão 2 da semana 6 sobre o Renascimento e Leonardo da Vinci

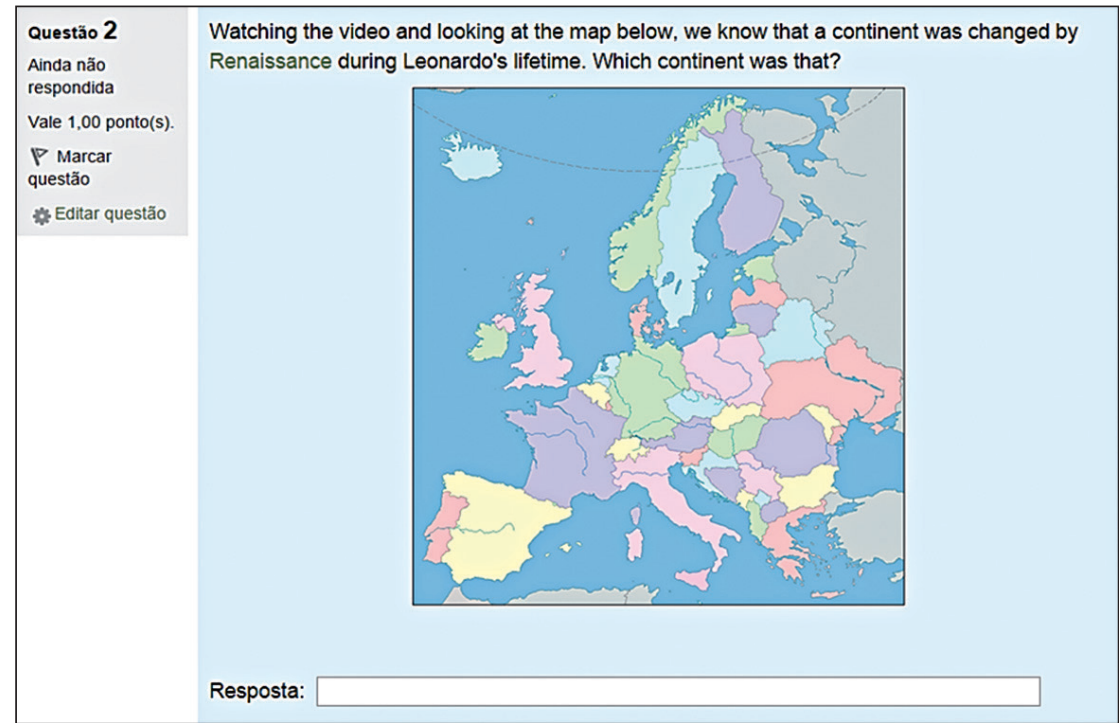

Fonte: Plataforma Moodle.

Para que a plataforma corrigisse a resposta fornecida pelo aluno, a professora a registrou de 4 formas diferentes: Europe, europe, Europa e europa. Como nesse tipo de questão, a professora pôde escolher qual a porcentagem de acerto de cada resposta, ela atribuiu porcentagens diferentes sendo: Europe (100\%), europe (90\%), Europa (50\%) e europa (40\%). No entanto, qualquer uma das 4 respostas fornecidas pelo aluno é considerada correta pela plataforma, mas a registrada como $100 \%$ é sempre indicada como a mais correta. 
Portanto, as respostas a esse tipo de questão foram registradas pela professora na plataforma de formas diferentes: em inglês, em português, com letra maiúscula e com letra minúscula. Ela optou pelo maior número possível de possibilidades de registro na plataforma para que essas variaçóes permitissem acerto maior por parte dos alunos.

É importante mencionar que mesmo nesse tipo de questão na qual a correção é feita automaticamente pela plataforma, há a possibilidade de o professor fornecer um comentário ao aluno depois dele realizar a tarefa. Esse comentário, por exemplo, pode ser feito com o intuito de esclarecer ao aluno o porquê da sua resposta ter sido considerada incorreta.

Esse tipo de questão foi um dos mais trabalhosos para a professora, pois a limitação de ter que registrar uma palavra ou apenas uma expressão como resposta correta caracterizava a atividade como de localização de informação e não como uma tarefa com foco no sentido e resultado comunicativo.

Depois de várias reformulações e adequações, em um trabalho conjunto entre professora-pesquisadora e orientadora, as atividades de resposta curta puderam ser elaboradas com foco no sentido, mas sem apresentar um resultado comunicativo.

\section{Escolha das ferramentas}

É relevante discutirmos que os dados mostraram que a professora não utilizou algumas ferramentas por não possuir capacidade técnica para isso, no entanto, constatamos que algumas delas (como o fórum de discussão ${ }^{7}$, por exemplo) ofereciam um potencial de interação muito maior que outras (o envio de arquivo ${ }^{8}$, por exemplo), no entanto, essas eram dominadas, mas não foram tão exploradas pela professora.

Isso nos mostra que, neste caso, não foram as limitaçôes técnicas que influenciaram diretamente as escolhas das ferramentas pela professora, mas a abordagem que ela possuía e suas experiências anteriores como aluna e professora de inglês.

Além disso, a aplicação do curso piloto fez com que a professora ficasse receosa em escolher ferramentas que solicitavam uma participação maior dos alunos como um grupo. Um exemplo disso é a escolha pelo fórum de discussão: apesar desta ferramenta ter sido utilizada, algumas tarefas poderiam ter gerado maior interação por parte dos alunos se a professora tivesse optado por utilizar um fórum ao invés de um envio de arquivo único, por exemplo.

Essa constatação pode ser vista na atividade exemplificada a seguir (Figura 4):

\footnotetext{
7 De acordo com Rozenfeld, Gabrielli e Soto (2009), o fórum de discussão tem como objetivo promover debates permitindo a realização de discussóes e interaçôes por meio da troca de mensagens escritas (assíncronas) pelos participantes.

8 "Permite que os estudantes enviem um arquivo de texto, imagem, arquivo compactado, planilhas eletrônicas, etc. conforme o solicitado na tarefa." (CRUZ, 2009, p.25).
} 
Figura 4 - Tarefa da semana 4 sobre Nikola Tesla

\section{Who was Nikola Tesla}

Hello.

In this part you are going to make a quiz about Nikola Tesla.

Frist, this quiz must have from 6 to 8 questions: 2 multiple choice answers, 2 open answers, 2 true or false and 2 sentences to fill in the gaps.

Second, answer the quiz.

Third, after the quiz has been answered, send the quiz to me using the icon QUIZ ABOUT NIKOLA TESLA.

Have a nice creative moment.

Denise

Fonte: Elaboração própria.

Esta tarefa requer que o aluno elabore um quiz sobre Nikola Tesla, sendo que as seis ou oito perguntas devem obedecer alguns critérios: duas devem ser de múltipla escolha, duas dissertativas, duas de verdadeiro e falso e duas para completar a frase dada.

Ao término da elaboraçáo da tarefa, o aluno deve enviar ao professor o quiz pronto, incluindo nele as respostas às perguntas elaboradas. Este envio deve ser feito por meio da ferramenta denominada envio de arquivo?

Essa escolha da professora pelo envio de arquivo, no qual apenas a professora e o aluno interagem um com o outro, poderia ter sido melhor explorada se ela optasse, por exemplo, pelo fórum de discussão. Nesse fórum, os alunos poderiam fazer perguntas aos seus colegas de curso e estes poderiam respondê-las e a professora poderia desempenhar o papel de mediadora da discussão, instigando os alunos a participarem, criando, assim, um ambiente bastante favorável à interação entre os usuários. Ao invés disso, a professora optou por uma ferramenta que limita bastante a interaçáo entre os participantes do curso, ficando esta interação restrita ao professor e ao aluno.

A escolha da ferramenta envio de arquivo em detrimento do fórum pode ter sido ocasionada pela experiência negativa da professora ao oferecer o curso piloto, já que dos 30 alunos participantes, apenas uma aluna o finalizou.

Esse fator pode ter influenciado a professora a escolher uma ferramenta que náo dependesse diretamente de um número considerável de participantes, pois, como a experiência com o curso piloto demonstrou um grande número de alunos evadidos, a professora considerou que a escolha de ferramentas como, por exemplo, o fórum, o qual necessita da participação dos alunos para que a interaçáo aconteça, deveria ser evitada para não comprometer a realização das atividades durante o curso em caso de grande

9 Por meio desta ferramenta, os alunos podem apresentar qualquer conteúdo digital (arquivos), como documentos em formato . $d o c$, .pdf, planilhas, imagens ou áudio e vídeos. 
evasão. Por outro lado, uma escolha como a da proposição de um fórum para aquela tarefa ou para outras poderia ter motivado mais os alunos a participarem e a interagirem.

A análise dos dados nos revela que as escolhas do professor ultrapassam questóes técnicas e objetivas, que a abordagem do professor, sua cultura de ensinar (ALMEIDA FILHO, 2002) e suas experiências anteriores como aluno e professor de línguas influenciam a sua docência.

\section{Considerações finais}

Diante do exposto neste artigo e dos resultados advindos da análise dos dados, defendemos que o professor que queira adotar um planejamento temático baseado em tarefas necessita primeiramente conhecer a teoria que embasa o planejamento temático baseado em tarefas, esse conhecimento pode advir da participaçáo do professor em programas de formação continuada, congressos e discussão com os pares. Em segundo, é necessário que o professor esteja bem preparado para utilizar a plataforma Moodle.

Queremos salientar que o pouco preparo da professora neste estudo para a utilizaçáo do PTBT e também da tecnologia para o ensino de línguas é sintomático da formação inicial e até mesmo continuada de professores em nosso país a qual está fortemente calcada no modelo de treinamento, sem oportunidades para os professores conhecerem, experimentarem e refletirem sobre diferentes formas e possibilidades de ensino. Defendemos com base em Almeida Filho (2002) que os professores precisam ter sua abordagem explicitada, com conceitos claros do que é língua, ensinar e aprender línguas.

Além disso, acreditamos que, mais importante que a plataforma e a disponibilidade de suas ferramentas, o papel do professor se faz fundamental nas escolhas as quais determinarão os tipos de experiências e a qualidade da interação que serão construídas entre professor e alunos ao longo do curso. Entendemos que as ferramentas podem, de certa forma, ajudar ou limitar o trabalho do professor, no entanto, reconhecemos que anterior ao papel das ferramentas, a abordagem do professor tem papel fundamental nas escolhas destas e na elaboração das atividades. Nesse sentido, apontamos para o trabalho de explicitação da abordagem do professor e para a importância da reflexão crítica para que o professor possa realizar mudanças em nível de abordagem, caso contrário, as mudanças podem ocorrer de forma superficial. A partir da análise dos dados apresentados, fica claro que a abordagem do professor é determinante das decisóes tomadas na elaboração do material, escolhas das ferramentas e implementação do curso.

A partir do reconhecimento de que cada contexto de ensino apresenta um perfil particular de alunos e que cada professor tem sua própria abordagem, sugerimos, a partir do estudo aqui apresentado, para o ambiente virtual de aprendizagem, alguns tópicos que podem auxiliar professores que queiram elaborar tarefas para o referido contexto:

$1^{\circ}$ conhecer a instituição e/ou o AVA onde o curso será oferecido;

$2^{\circ}$ conhecer o perfil dos alunos;

$3^{\circ}$ levantar as necessidades dos discentes; 
$4^{\mathrm{o}}$ escolher um tema(s) relevante(s) e significativo para os alunos;

$5^{\circ}$ embasar-se teoricamente sobre PTBT e tarefas com foco no sentido;

$6^{\circ}$ seguir uma ou várias tipologias de tarefa;

$7^{\circ}$ (se possível) aplicar um curso piloto;

$8^{\circ}$ aprimorar o material atendendo aos princípios desse tipo de planejamento;

$9^{\circ}$ utilizar o material e fazer alterações quando necessário durante o uso;

$10^{\circ}$ atender às necessidades reveladas pelos alunos ou detectadas pela professora quanto ao estudo da forma.

É relevante destacar que esses tópicos são apenas sugestôes que podem e/ou devem ser adequados de acordo com as especificidades de cada contexto de ensino. Viemos, aqui, portanto, apresentar sugestóes com o intuito de auxiliar os professores que queiram implementar um PTBT em sala de aula (presencial e /ou virtual) de línguas, sem termos a intenção de sermos prescritivos.

Apontamos também para a necessidade de mais pesquisas utilizando o PTBT (não apenas no contexto virtual, mas também presencial), as quais possam contribuir com mais compreensóes sobre a escolha de outras ferramentas e adotem outros ambientes virtuais de aprendizagem, além do Moodle, para o oferecimento de cursos. Essas pesquisas trarâo novas constataçóes que seráo imprescindíveis para contribuir para o processo de ensino e aprendizagem de língua inglesa.

\section{AN ONLINE ENGLISH COURSE USING A TASK-BASED LANGUAGE TEACHING: THE TEACHER AS AN AGENT OF CHOICE}

- ABSTRACT: Since the advent of the new technologies, the language teaching came across to a virtual learning environment. In an attempt to consider the principles of the communicative approach (ALMEIDA FILHO, 2002, 2005, 2012) and the task-based language teaching (TBLT) (SKEHAN, 1996; XAVIER 1999, 2007; BARBIRATO 1999, 2005) an online English course was offered in the Moodle platform to students of technical, technological and Undergraduate courses from a Federal institution of technology. The theme chosen for the course was Inventors and Inventions and the thematic units contemplated aspects of Nikola Tesla's and Leonardo da Vincis lives and inventions. The purpose of this article, therefore, is to present and discuss results derived from a doctoral research analyzing the teacher's role in the preparation of thematic material based on tasks for the online English course in the Moodle. The data analysis pointed out to the very important role of the teacher in the challenges and choices along the process of the material elaboration.

- KEY-WORDS: TBLT. English Teaching and Learning. Moodle Plataform. 


\section{REFERÊNCIAS}

ALMEIDA, M. E. B. Educação a distância na internet: abordagens e contribuiçóes dos ambientes digitais de aprendizagem. Educação e Pesquisa, São Paulo, v.29, n.2, p.327-340, jul./dez. 2003.

ALMEIDA FILHO, J. C. P. Quatro estaçóes no ensino de línguas. Campinas: Pontes, 2012. ALMEIDA FILHO, J. C. P. Linguística aplicada, ensino de línguas e comunicação. Campinas: Pontes, 2005.

ALMEIDA FILHO, J. C. P. Dimensóes comunicativas no ensino de línguas. 3.ed. Campinas: Pontes, 2002.

ALMEIDA FILHO, J. C. P.; BARBIRATO, R. C. Ambientes comunicativos para aprender língua estrangeira. Trabalhos de Linguística Aplicada, Campinas, v.36, p.23-42, jul./dez. 2000 .

AMARAL, A.; NATAL, G.; VIANA, L. Netnografia como aporte metodológico na pesquisa em comunicação digital. Revista FAMECOS, Porto Alegre, n. 20, p.34-40, dez. 2008.

BARBIRATO, R. C. A tarefa como ambiente para aprender LE. 1999. Dissertação (Mestrado em Linguística Aplicada) - Instituto de Estudos da Linguagem, Universidade Estadual de Campinas, Campinas, 1999.

BARBIRATO, R. C. O uso de atividades comunicativas na aula de LE: alguns resultados. Contexturas: Ensino Crítico de Língua Inglesa, [S.1.], n.5, p.27-44, 2000.

BARBIRATO. R. C. Tarefas geradoras de insumo e qualidade interativa na construçáo do processo de aprender LE em contexto inicial adverso. 2005. Tese (Doutorado em Linguística Aplicada) - Instituto de Estudos da Linguagem, Universidade Estadual de Campinas, Campinas, 2005.

COLE, J.; FOSTER, H. Using Moodle: teaching with the popular open source course management system. 2nd ed. Sebastopol: O’Reilly Community Press, 2008.

CRUZ, T. R. Manual de introduçáo ao uso do Moodle para professores e tutores. PLAGEDER Núcleo de EAD Universidade Federal do Rio Grande do Sul, 2009. Disponível em: <http://www.ufrgs.br/nucleoead/download/manualMoodle.pdf>. Acesso em: 10 jan. 2014.

DOUGIAMAS, M. Improving the effectiveness of tools for Internet based education. In: ANNUAL TEACHING LEARNING FORUM, 9., 2000, Perth. Proceedings... Perth: Curtin University of Technology, 2000. Disponível em: <http://ctl.curtin.edu.au/events/ conferences/tlf/tlf2000/dougiamas.html>. Acesso em: 15 jun. 2014.

FRANCESCHINI, A. R. A relaçáo da competência comunicativa com o planejamento temático baseado em tarefas em um curso de português língua estrangeira. 2014. Dissertação (Mestrado em Linguística) - Universidade Federal de São Carlos, São Carlos, 2014. 
FRANCO, C. P. O uso de um ambiente virtual de aprendizagem no ensino de inglês: além dos limites da sala de aula presencial. 2009. Dissertação (Mestrado em Linguística Aplicada) Faculdade de Letras, Universidade Federal do Rio de Janeiro, Rio de Janeiro, 2009.

FROST, R. A task-based approach. Turkey: British Council, 2006.

GONZALES, M. Fundamentos da tutoria em educação a distância. São Paulo: Avercamp, 2005.

MASSAROTTO, F. A.; SOUZA, A.; BARBIRATO, R. C. Vivência comunicativa na aula de LE do ensino médio: alguns resultados. Revista Horizontes de Linguística Aplicada, Brasília, v. 8 , n. 1, p. 113-126, 2009.

MERCADO, L. P. Pesquisa qualitativa online utilizando a etnografia virtual. Revista Teias, [Rio de Janeiro], v. 13, n. 30, p.169-183, 2012.

MOITA-LOPES, L. P. Oficina de linguística aplicada. Campinas: Mercado das Letras, 1996. MOORE, M,; KEARSLEY, G. Educação a distância: uma visão integrada. São Paulo: Cengage Learning, 2008.

RICHARDS, J. C. Communicative language teaching today. Singapore: SEAMEO, 2005.

ROZENFELD, C. C. de F; GABRIELLI, K. S.; SOTO, U. O fórum educacional em cursos virtuais de LE como ferramenta de interação: uma análise crítica de duas experiências. In: ENCONTRO NACIONAL SOBRE HIPERTEXTO, 3., 2009, Belo Horizonte. Anais... Belo Horizonte: [s.n.], 2009 Disponível em: <https:/www.ufpe.br/nehte/hipertexto2009/ anais/m-o/o-forum\%20-ducacional.pdf>. Acesso em: 20 fev. 2015.

SKEHAN, P. Task-based instruction. Language Teaching, Cambridge, v.36, p.1-14, 2003.

SKEHAN, P. A framework for the implementation of task-based instruction. Applied Linguistics, Oxford, v.17, p.38-62, 1996.

XAVIER, R. P. Revisitando o conceito de tarefas comunicativas. Caderno de Letras, Pelotas, v. 13, p. 35-46, 2007.

XAVIER, R. P. Elaboraçáo, implementação e avaliaçáo de um programa temático de inglês baseado em tarefas. 1999. Tese (Doutorado em Linguística Aplicada) - Universidade Estadual de Campinas, Campinas, 1999.

WIDDOWSON, H. O ensino de línguas para a comunicação. Campinas: Pontes, 1991.

Recebido em 23/05/2016

Aprovado em 04/08/2016 